\title{
Erratum to: Productivity spillovers from FDI and the role of domestic firm's absorptive capacity in South Korean manufacturing industries
}

\section{Minjung Kim ${ }^{1}$}

\section{Erratum to: Empir Econ (2015) 48:807-827 DOI 10.1007/s00181-014-0804-z}

As desired by the author, the corrected affiliation is given here.

\section{Kim (凶)}

Division of Economics, Wonkwang University, Iksan, Republic of Korea e-mail:kimmj@wku.ac.kr

The online version of the original article can be found under doi:10.1007/s00181-014-0804-z.

$\bowtie \quad$ Minjung Kim

kimmj@wku.ac.kr

1 Division of Economics, Wonkwang University, Iksan, Republic of Korea 